\title{
Resistance of Leishmania (Leishmania) amazonensis and Leishmania (Viannia) braziliensis to nitric oxide correlates with disease severity in Tegumentary Leishmaniasis
}

\author{
Angela Giudice*1, Ilza Camada1, Paulo TG Leopoldo², Júlia MB Pereira1, \\ Lee W Riley ${ }^{3}$, Mary E Wilson ${ }^{4}$, John $\mathrm{L} \mathrm{Ho}^{5}$, Amelia Ribeiro de Jesus ${ }^{1}$, \\ Edgar $\mathrm{M}$ Carvalho ${ }^{1}$ and Roque P Almeida ${ }^{1}$
}

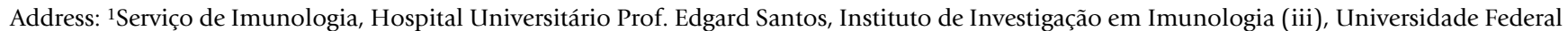
da Bahia, Salvador, Bahia, Brazil, ${ }^{2}$ Departamento de Fisiologia, Universidade Federal de Sergipe, Aracaju, Sergipe, Brazil, ${ }^{3}$ Division of Infectious Diseases, School of Public Health, University of California, Berkeley, CA, USA, ${ }^{4}$ Department of Internal Medicine, Microbiology, University of Iowa College of Medicine, Iowa City, IA, USA and ${ }^{5}$ Department of Medicine, Division of International Medicine and Infectious Diseases, Weill Medical College of Cornell University, New York, NY, USA
\end{abstract}

Email: Angela Giudice* - agiudice@ufba.br; Ilza Camada - imuno@ufba.br; Paulo TG Leopoldo - pauloleopoldo@bol.com.br; Júlia MB Pereira - juliambp@yahoo.com.br; Lee W Riley - lwriley@berkeley.edu; Mary E Wilson - mary-wilson@uiowa.edu; John L Ho - jlho@med.cornell.ed; Amelia Ribeiro de Jesus - amelia@ufba.br; Edgar M Carvalho - edgar@ufba.br; Roque P Almeida - roque@ufba.br

* Corresponding author

Published: 22 February 2007

BMC Infectious Diseases 2007, 7:7 doi:10.1186/147|-2334-7-7
Received: 28 June 2006

Accepted: 22 February 2007

This article is available from: http://www.biomedcentral.com//47I-2334/7/7

(C) 2007 Giudice et al; licensee BioMed Central Ltd.

This is an Open Access article distributed under the terms of the Creative Commons Attribution License (http://creativecommons.org/licenses/by/2.0), which permits unrestricted use, distribution, and reproduction in any medium, provided the original work is properly cited.

\begin{abstract}
Background: Nitric oxide (NO) plays a pivotal role as a leishmanicidal agent in mouse macrophages. NO resistant Escherichia coli and Mycobacterium tuberculosis have been associated with a severe outcome of these diseases.

Methods: In this study we evaluated the in vitro toxicity of nitric oxide for the promastigote stages of Leishmania (Viannia) braziliensis and Leishmania (Leishmania) amazonensis parasites, and the infectivity of the amastigote stage for human macrophages. Parasites were isolated from patients with cutaneous, mucosal or disseminated leishmaniasis, and NO resistance was correlated with clinical presentation.
\end{abstract}

Results: Seventeen isolates of $L$. (L.) amazonensis or L. (V.) braziliensis promastigotes were killed by up to $8 \mathrm{mM}$ of more of $\mathrm{NaNO}_{2}(\mathrm{pH} 5.0)$ and therefore were defined as nitric oxide-susceptible. In contrast, eleven isolates that survived exposure to $16 \mathrm{mM} \mathrm{NaNO}_{2}$ were defined as nitric oxideresistant. Patients infected with nitric oxide-resistant Leishmania had significantly larger lesions than patients infected with nitric oxide-susceptible isolates. Furthermore, nitric oxide-resistant $L$. (L.) amazonensis and $L$. (V.) braziliensis multiplied significantly better in human macrophages than nitric oxide-susceptible isolates.

Conclusion: These data suggest that nitric oxide-resistance of Leishmania isolates confers a survival benefit for the parasites inside the macrophage, and possibly exacerbates the clinical course of human leishmaniasis. 


\section{Background}

Leishmaniasis is a parasitic disease caused by the Leishmania spp. protozoa, transmitted to the skin of a mammalian host during the bite of an infected female sand fly vector. Infections range in severity from asymptomatic to disfiguring forms of tegumentary and potentially fatal visceral leishmaniasis $[1,2]$. American tegumentary leishmaniasis (ATL) presents a spectrum of clinical manifestations characterized by cutaneous (CL), mucosal (ML), disseminated (DL) and diffuse cutaneous leishmaniasis (DCL). The major Leishmania species that cause ATL in the New World are $L$. (V.) braziliensis, L. (V.) guyanensis, L. (L.) amazonensis and $L$. (L.)mexicana. The typical clinical manifestation of American CL is a single ulcerated lesion with elevated borders, frequently located on the inferior limbs [3]. Mucosal leishmaniasis (ML) is a destructive disease that predominantly affects the nasopharyngeal mucosa. The disease is most common in areas of $L$. (V.) braziliensis transmission and usually occurs months or years after cutaneous leishmaniasis [4]. Disseminated leishmaniasis (DL) has been reported almost exclusively in northern and northeastern Brazil. DL is characterized by the appearance of multiple pleomorphic lesions in two or more noncontiguous areas of the body [5].

Leishmania is a digenetic protozoan with an extracellular flagellated promastigotes form which replicates and matures to the infectious metacyclic form in the gut of the sand fly vector. The promastigotes is transmitted to a mammalian host during the bite of an infected sand fly. Promastigotes undergo facilitated phagocytosis by a macrophage and convert to the obligate intracellular amastigote life stage $[6,7]$. Amastigotes survive in macrophage phagolysosomes, a hostile environment for many microbes. Leishmania spp. must undergo profound biochemical and morphological adaptations to survive successfully and multiply within macrophages [7]. The mechanisms through which the parasite resists killing within the toxic environment of the phagolysosome remain incompletely defined.

Leishmaniasis is controlled through cell-mediated immune defenses [8]. Murine models have illustrated that macrophages produce IL-12, which induces CD4+ T cells and NK cells to release interferon gamma (IFN- $\gamma$ ), polarizing the immune response toward a type 1 (Th1 type) phenotype $[9,10]$. In murine systems, IFN- $\gamma$ has been shown to synergize with another macrophage derived cytokine, tumor necrosis factor alpha (TNF- $\alpha$ ), activating nitric oxide synthase (iNOS or NOS2) to produce nitric oxide $\left(\mathrm{NO}^{\bullet}\right)$ with resultant in killing of intracellular parasites [11-13]. $\mathrm{NO}^{\bullet}$ is generated from the oxidation of the terminal guanidine nitrogen atoms of the L-arginine by NADPH dependent enzyme nitric oxide synthase (NOS) [14]. In murine models of leishmaniasis, $\mathrm{NO}^{\bullet}$-dependent mechanisms have been shown to be critical for control of Leishmania infection[15,16]. The role of NO ${ }^{\bullet}$ in leishmanicidal activity of human macrophages, has been debated [17]. However, recent data suggest that $\mathrm{NO}^{\bullet}$ plays a role in the response of human macrophages to intracellular infections, but the nature of this role is not yet clear $[18,19]$.

Putative $\mathrm{NO}^{\bullet}$-mediated leishmanicidal actions in eukaryotic cells include inhibition of mitochondrial respiration, inactivation of peroxidases, increasing susceptibility to oxidant damage, inhibition of glycolysis, mutation of DNA, inhibition of DNA repair and synthesis, S-nitrosylation, ADP-ribosylation, tyrosine nitration of proteins, disruption of Fe-S clusters, zinc fingers or heme groups, and peroxidation of membrane lipids $[20,21]$. The Leishmania spp. possesses unique antioxidant mechanisms and enzymes. Notably, they convert their abundant GSH stores to trypanothione (TSH) and use TSH reductase/oxidase systems for redox cycling [22]. The protozoa express an iron superoxide dismutase (SOD) but not a manganese SOD, and they have peroxidoxins for handling oxidative stress [23-26]. Nonetheless, oxidant resistance in these parasites are inducible [27], and one expects these systems are susceptible to inactivation by oxidant species similar to other eukaryotes.

Resistance to nitric oxide has been described in E. coli and M. tuberculosis. Resistant isolates have been associated with a more severe outcome of disease than that caused by non-resistant strains [28]. However, natural NO• resistance in Leishmania spp. isolates has not previously been described. In the present study, we evaluated the effect of $\mathrm{NO}^{\bullet}$ generated from $\mathrm{NaNO}_{2}(\mathrm{pH} 5.0)$ on the viability of $L$. (V.) braziliensis and L. (L.) amazonensis promastigotes. NO• resistant Leishmania amastigotes multiplied significantly better than nitric oxide-susceptible parasites during infection of human macrophages. Furthermore, NO• resistance was directly associated with lesion size, a clinical measure of disease severity.

\section{Methods \\ Parasites}

L. (L.) amazonensis and L. (V.) braziliensis parasites were obtained by needle aspiration of lesions from patients with CL, DL or ML. Parasites for study were randomly selected from frozen nitrogen Leishmania stocks by investigators blinded to the Leishmania species or clinical form of leishmaniasis. Parasites were speciated by isoenzyme electrophoresis and monoclonal antibodies as described. This analysis was performed by Departamento de Bioquimica e Biologia Molecular, Instituto Oswaldo Cruz, FIOCRUZ, Rio de Janeiro, Brazil [29]. 


\section{Isolation and cultivation of L. (V.) braziliensis and L. (L.) amazonensis}

Parasite isolates $L$. (V.) braziliensis $(\mathrm{n}=17)$ and $L$. $(L$.) amazonensis $(\mathrm{n}=11)$ were initially cultivated from patient specimens in tubes with biphasic medium (NNN) consisting of rabbit blood agar overlaid with liver infusion tryptose (LIT), supplemented with $10 \%$ heat inactivated fetal bovine serum medium (Sigma Chemical Co., St. Louis, $\mathrm{MO}$ ). Following isolation, parasite isolates were cryopreserved. The time of storage of the selected strains was similar ( $p>0.05)$. The parasites selected for study had not been previously passaged in liquid culture medium before the beginning of the present study. After selection, parasite isolates were expanded in Schneider's insect medium (Sigma) pH 7.2 supplemented with $10 \%$ fetal bovine serum (FBS) and $2 \%$ male human urine at $25^{\circ} \mathrm{C}$ (complete Schneider medium).

\section{Promastigote NO' susceptibility assays Thymidine incorporation}

L. (L.) amazonensis $(\mathrm{n}=10)$ and L. (V.) braziliensis $(\mathrm{n}=6)$ promastigotes in log phase growth were adjusted to $2 \times$ $10^{7}$ parasites/ml in Hanks' balanced solution (HBBS Sigma, pH 5.0). Twenty $\mu$ l aliquots containing $4 \times 10^{5}$ parasites were placed in 96-well $U$ shaped plates containing

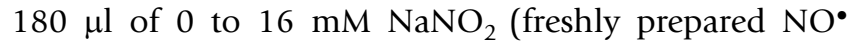
donor) in Hanks Balanced Solution, pH 5.0. After 4 hours incubation at $25^{\circ} \mathrm{C}$, plates were centrifuged $(700 \times \mathrm{g}$ for 10 minutes). The viability of the remaining parasites was assessed by incubation for $20 \mathrm{hr}$ in $200 \mu \mathrm{l}$ of complete Schneider's medium with $1 \mu \mathrm{Ci}$ of Thymidine $\left({ }^{3} \mathrm{H}-\mathrm{TdR}\right.$; ICN Immunochemicals, Costa Mesa, CA, USA) to allow them to enter logarithmic growth. Thymidine incorporation was assessed on a $\beta$ counter.

\section{MTT assay}

L. (L.) amazonensis $(\mathrm{n}=5)$ and $L$. (V.) braziliensis promastigotes $(n=14)$ in log phase growth were adjusted to $5 \times$ $10^{7}$ parasites/ml in Hanks' balanced solution (HBBS Sigma, pH 5.0). Twenty- $\mu$ l aliquots were incubated in 180 $\mu \mathrm{l}$ of 0 to $16 \mathrm{mM} \mathrm{NaNO}_{2}$ (freshly prepared $\mathrm{NO} \cdot$ donor) in Hanks Balanced Solution, pH 5.0 in 96-well U shaped plates. After 4 hrs incubation at $25^{\circ} \mathrm{C}$, plates were centrifuged (700 $\times \mathrm{g}$ for 10 minutes) and parasites were resuspended with $200 \mu \mathrm{l}$ of complete Schneider medium. After an additional $20 \mathrm{hrs}$ at $25^{\circ} \mathrm{C}$ and centrifugation, parasite viability was measured by incubation in $0.5 \mathrm{mg} / \mathrm{ml}$ of MTT [3-(4,5-dimetthythiazol-2-yl)-2,5-diphenyltetiazolium bromide] in Hanks solution, pH 7.0 at $25^{\circ} \mathrm{C}$ for 4 hrs, followed by dilution in an equal volume $0.04 \mathrm{~N} \mathrm{HCl}$ in isopropanol. Living mitochondria convert MTT to dark blue formazan that is soluble in acid-isopropanol and detectable on a microplate reader at $540 \mathrm{~nm}$. The percentage of viability was calculated from the OD ratio of untreated versus $\mathrm{NO}^{\bullet}$-treated parasites $\times 100$ [27]. For each parasite isolate 3 experiments at least were performed to test for $\mathrm{NO}^{\bullet}$ susceptibility. The thymidine incorporation and MTT assays were done with 28 Leishmania isolates of both species. Seven isolates were tested with both methods.

The virulence of Leishmania spp. is highest in stationary phase, or metacyclic organisms. Nonetheless the MTT and $\left[{ }^{3} \mathrm{H}\right]-\mathrm{TdR}$ uptake assays are most sensitive for log phase organisms. We previously reported that these assays of virulence and oxidant sensitivity in log phase correlate with oxidant sensitivity and virulence in stationary phase organisms $[27,30]$. As such, viability assays were performed using log phase promastigotes, whereas studies of interactions with mammalian cells utilized stationary phase organisms.

\section{Macrophage cultures}

Peripheral blood mononuclear cells (PBMCs) were isolated from the peripheral blood of three different healthy human donors. Briefly, heparinized blood was diluted 1:2 with $0.15 \mathrm{M} \mathrm{NaCl}$ and overlaid on Ficoll Hypaque (LSM; Organon Teknika corporation, Durham, NC, USA). After centrifugation, mononuclear cells were collected at the plasma - Ficoll interface, washed three times and resuspended in RPMI 1640 with 10\% heat inactivated human AB serum, $100 \mathrm{U}$ penicillin/ml and $100 \mu \mathrm{g}$ streptomycin/ $\mathrm{ml}$ (complete medium) (GIBCO BRL, Grand Island, NY). Monocytes were separated from $1 \times 10^{6}$ PBMCs by adherence to 8 well Lab Tek plates for $2 \mathrm{~h}$ at $37^{\circ} \mathrm{C}, 5 \% \mathrm{CO}_{2}$, non-adherent cells were removed by washing, and complete medium was added. Adherent monocytes differentiated to macrophages over six days incubation at $37^{\circ} \mathrm{C}$ in $5 \% \mathrm{CO}_{2}$.

\section{Macrophage infection}

One $\mathrm{NO}^{\bullet}$-resistant and one $\mathrm{NO}^{\bullet}$-susceptible isolate each of L. (V.) braziliensis and L. (L.) amazonensis (total 4 isolates)were selected for the macrophage infection assays. Three to 4 replicate assays were performed for each isolate. Promastigotes were maintained at $25^{\circ} \mathrm{C}$ in Schneider's insect medium (Sigma) pH 7.2 supplemented with $10 \%$ fetal bovine serum (FBS) and 2\% human male urine at $25^{\circ} \mathrm{C}$ (complete Schneider's medium). Promastigotes in stationary- phase of growth were used in all experiments. All experiments were performed in 3 assays for L. (V.) braziliensis and 4 assays for L. (L.) amazonensis using PBMC/ macrophages from 3 different healthy volunteers. The same donors were used for the different species so that the results are directly comparable. After Six-day monocytederived macrophages were infected with a 10:1 ratio of stationary - phase promastigotes to macrophages for 2 hours at $35^{\circ} \mathrm{C}, 5 \% \mathrm{CO}_{2}$. Extracellular parasites were removed by gentle washing and infected macrophages were maintained for up to $96 \mathrm{~h}$. Cells were stained with 
Giemsa and the infection levels were enumerated microscopically by counting the infected cells and parasites per 100 macrophages by three independent observers, blinded to the experimental conditions.

\section{Epidemiological and clinical evaluations}

Clinical characteristics of the patients such as age, lesion size, Montenegro skin reaction, duration of disease and clinical manifestation of leishmaniasis were determined from clinical records after characterizing the NO• susceptibility of isolates. Adequate data were available for fourteen patients. Most patients were identified and diagnosed at the Corte de Pedra Health Post, located in an endemic area for cutaneous leishmaniasis situated in the southeast of the state of Bahia, Brazil. The remainder of patients was referred to the University Hospital Prof. Edgard Santos of the Federal University of Bahia, Brazil. This study was approved by the Ethical Committee of the Hospital Universitário Prof. Edgard Santos and an informed consent was obtained from all participants or their parents or guardians if patients were less than 18 years old.

\section{Statistical analysis}

Student's t-test was used to compare the age, lesion appearance, and human macrophage infection studies. Lesion size and Montenegro diameter were analyzed by Mann-Whitney nonparametric test. Fischer's Exact test was used to compare $\mathrm{NO}^{\bullet}$-resistant versus $\mathrm{NO}^{\bullet}$-susceptible $L$. (L.) amazonensis and $L$. (V.) braziliensis. An alpha of $5 \%$ ( $\mathrm{p} \leq 0.05)$ was considered for statistical significance (two tailed). Statistical analysis was performed using GraphPad Prism 3.0 (GraphPad software, San Diego, CA, USA).

\section{Results \\ Evaluation of Leishmania spp. promastigotes resistance to NO' and correlation with clinical disease}

The susceptibility of $L$. $(L)$ amazonensis $(\mathrm{n}=11)$ and $L .(V)$ braziliensis $(\mathrm{n}=17)$ promastigotes to $\mathrm{NO}^{\bullet}$ toxicity was evaluated using two measures of parasite viability: first, the rate of $\left[{ }^{3} \mathrm{H}\right]$-thymidine incorporation into parasite DNA, and second, a colorimetric measure of mitochondrial activity according to MTT metabolism to formazan. Our preliminary titrations led us to a definition of $\mathrm{NO}^{\bullet}$ susceptibility as measured viability that is less than $5 \%$ of control parasites after exposure to $8 \mathrm{mM} \mathrm{NaNO}_{2}$. Using this definition, we found that $73 \%$ ( 8 of 11 ) of the $L$. (L.) amazonensis isolates and $18 \%$ (3 of 17) L. (V.) braziliensis isolates were resistant to $\mathrm{NO}^{\bullet}$ (Table 1 ). Of the $\mathrm{NO}^{\bullet}$-susceptible isolates, a titration of $\mathrm{NaNO}_{2}$ from $0.25 \mathrm{mM}$ to 16 $\mathrm{mM}$ showed concentration-dependent killing of susceptible isolates with nearly $100 \%$ killing at $8 \mathrm{mM} \mathrm{NaNO}_{2}$. In contrast, $\mathrm{NO}^{\bullet}$-resistant $L$. (L.) amazonensis and $L$. (V.) braziliensis isolates remained viable even in $16 \mathrm{mM} \mathrm{NaNO}_{2}$ (Figure 1, Tables 2, 3, 4 and 5). The storage time in liquid nitrogen of the $\mathrm{NO}^{\bullet}$-susceptible isolates (mean $\pm \mathrm{SD}=6.6$ \pm 3.2 years) was similar to the $\mathrm{NO} \bullet$ resistant isolates $(7.8$ \pm 2.7 years), $\mathrm{p}=0.3$.

\section{Infection in vitro of human macrophages}

Two isolates each of $L$. (L.) amazonensis and $L$. (V.) braziliensis, one $\mathrm{NO}^{\bullet}$-resistant and one $\mathrm{NO}^{\bullet}$-susceptible were evaluated for their ability to infect and proliferate within culture-derived human macrophages in vitro. The data demonstrate that $\mathrm{NO}^{\bullet}$-resistant and $\mathrm{NO}^{\bullet}$-susceptible $L$ (L.) amazonensis and L. (V.) braziliensis infected human macrophages with similar efficacy, as demonstrated by a similar degree of macrophage infection at 2 hours with all isolates (Figure 2, p > 0.05). Beginning $24 \mathrm{~h}$ after infection, intracellular macrophage killing of $\mathrm{NO}^{\bullet}$-susceptible parasites of both Leishmania species was evident from the declining parasite numbers. In contrast, $\mathrm{NO}^{\bullet}$-resistant parasites either maintained an unchanged infection level [L. (V.) braziliensis] or multiplied [L. (L.) amazonensis]. Thus, at the $96 \mathrm{hr}$ time point the numbers of intracellular NO-resistant $L$. (L.) amazonensis amastigotes was significantly higher than $\mathrm{NO}^{\bullet}$-susceptible parasites (mean $\pm \mathrm{SD}$ $=534 \pm 164$ versus $219 \pm 75, \mathrm{p}=0.01)$. Similarly, the numbers of intracellular $\mathrm{NO}^{\bullet}$-resistant $L$. $(V$.) braziliensis was significantly higher than $\mathrm{NO}^{\bullet}$-susceptible parasites (mean $\pm \mathrm{SD}=315 \pm 56$ versus $87 \pm 3, \mathrm{p}=0.002$ ) (Figure $2 \mathrm{~A}$ and $2 \mathrm{~B}$ ). When the results were calculated as the percent of cells infected, data revealed there were also significantly higher numbers of macrophages infected by $\mathrm{NO}^{\bullet}$ resistant compared to $\mathrm{NO}^{\bullet}$-susceptible $L$. (L.) amazonensis (mean $\pm \mathrm{SD}=68 \pm 5.2$ versus $47 \pm 10, \mathrm{p}=0.008)$, and higher numbers of macrophages infected with $\mathrm{NO}^{\bullet}-$ resistant versus susceptible $L$. (V.) braziliensis ( $61 \pm 4$ versus $32 \pm 5, \mathrm{p}=0.002$ ). This suggests that parasites spread to new cells in the macrophage monolayer in vitro (Figure $2 \mathrm{C}$ and 2D). Although we did not evaluate the mechanisms, these data suggest that $\mathrm{NO}^{\bullet}$-resistant amastigotes survive and multiply in resting human macrophages better than susceptible isolates.

\section{Epidemiological and clinical evaluations}

Clinical records were available for full analysis for 14 isolates from patients with CL. Evaluation of these records indicated that patients infected with $\mathrm{NO}^{\bullet}$-resistant $L$. (L.)

Table I: Relation between Leishmania species and NOresistance

\begin{tabular}{lccc}
\hline Isolates & Susceptible & Resistant & Total \\
\hline L. amazonensis & 3 & $8(73 \%)$ & 11 \\
L. braziliensis & 14 & $3(18 \%)$ & 17 \\
Total & 17 & 11 & 28 \\
\hline
\end{tabular}

Differences between the proportions were statistically significant (Fisher Exact Test, $\mathrm{p}<0.006$ ) 

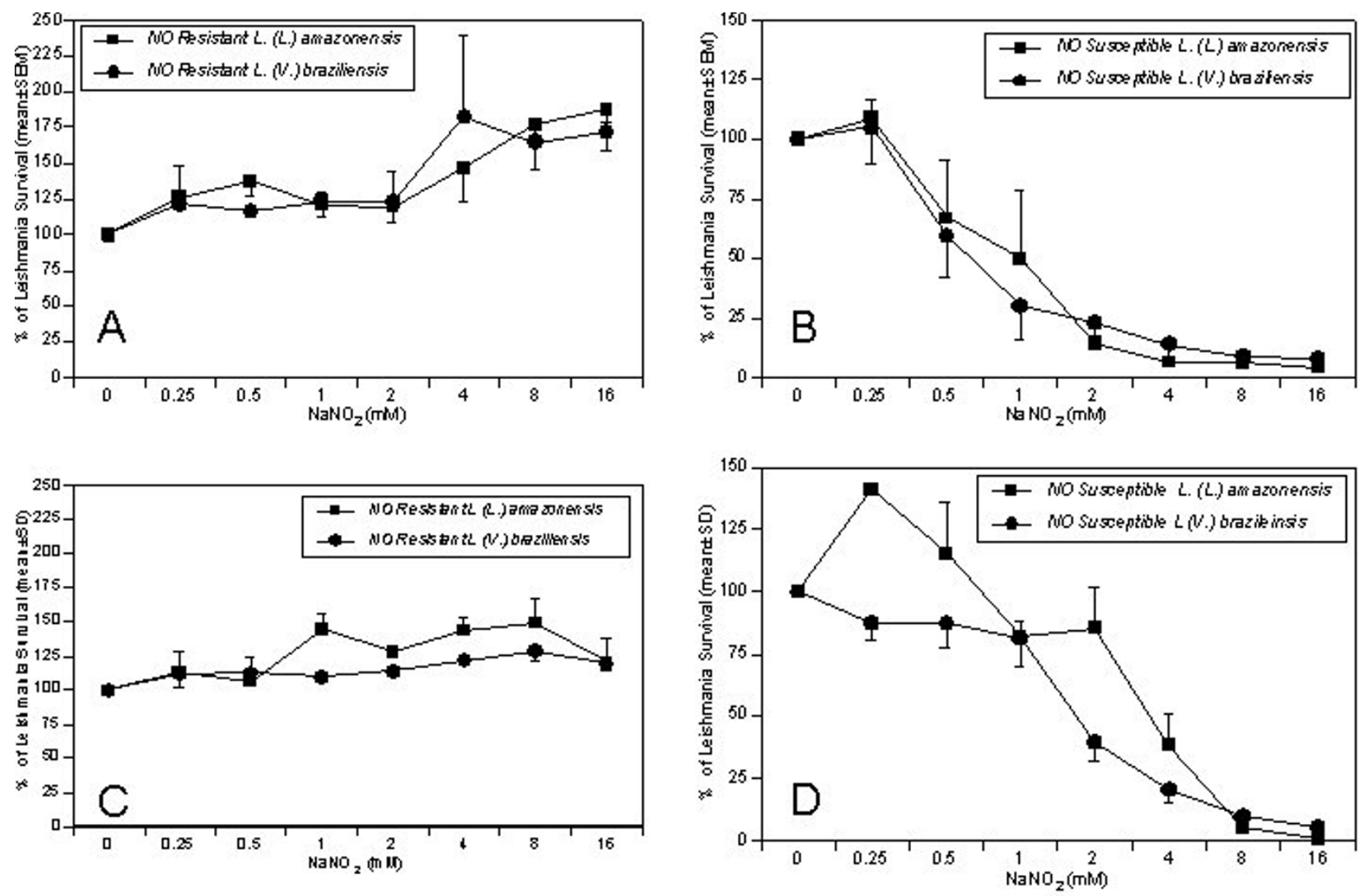

Figure I

Survival of L. (V.) braziliensis and L.(L.) amazonensis promastigotes in increasing concentrations of NO' measured by Thymidine incorporation ( $\mathbf{A}$ and $\mathbf{B}$ ) and colorimetric $\mathbf{M T T}$ assay (C and D). Promastigotes in HBSS pH 5.0 were exposed to increasing $\mathrm{NaNO}_{2}$ concentrations $(0.25-16 \mathrm{mM})$ for 4 hours. Viability was measured by incorporation of ${ }^{3} \mathrm{H}$ TdR or conversion of MTT of formazan as described in the Methods section. Data in panels $A$ and $B$ represent mean \pm SEM percentage survival for (IA) 8 resistant $L$. (L.) amazonensis and two resistant $L$. (V.) braziliensis isolates, (I B) two susceptible $L$. (L.) amazonensis and 4 susceptible $L$. (V.) braziliensis isolates as measured by thymidine incorporation. Data in panels $C$ and $D$ represent the mean \pm SEM MTT conversion for (IC) $3 \mathrm{NO}^{\circ}-$ resistant $L$. (L.) amazonensis and $2 \mathrm{NO}^{\circ}$-resistant $L^{\circ}$. (V.) braziliensis isolates, or (ID) 2 susceptible $L$. (L.) amazonensis and 12 susceptible $L$. (V.) braziliensis isolates.

amazonensis or L. (V.) braziliensis isolates presented with a larger ulcers (mean \pm SD diameter $=43.2 \pm 18 \mathrm{~mm}$ ) than patients who had $\mathrm{NO}^{\bullet}$-susceptible parasites $(18.0 \pm 8$ $\mathrm{mm}, \mathrm{p}=0.01$; Figure 3 ). However, no significant differences between these patient groups were observed in the time from first lesion detection by the patient to the time of clinical evaluation by a physician (mean $\pm \mathrm{SD}=48 \pm 34$ days for $\mathrm{NO}^{\bullet}$-sresistant versus $32 \pm 25$ days for $\mathrm{NO}^{\bullet}$-susceptible isolates, $\mathrm{p}=0.3$ ). Although not significant possibly due to small numbers, $50 \%$ of patients with $\mathrm{ML}$, a more severe form of disease, had $\mathrm{NO}^{\bullet}$-resistant isolates compared to $31 \%$ of the $\mathrm{CL}$ patients had $\mathrm{NO}^{\bullet}$-resistant isolates. Both isolates from patients with DL were $\mathrm{NO} \bullet$ susceptible. There was no significant difference between characteristics of the ulcer at initial presentation, patient age, or size of the Montenegro skin reaction to Leishmania antigen between patients harboring $\mathrm{NO}^{\bullet}$-resistant versus $\mathrm{NO}^{\bullet}$-susceptible Leishmania isolates.

\section{Discussion}

In the current study we demonstrated for the first time that some isolates of both $L$. (V.) braziliensis and $L$. (L.) amazonensis promastigotes are resistant to killing by nitric oxide. Additionally, we showed that the amastigotes from two resistant isolates survived and multiplied better than susceptible isolates in resting human macrophages in vitro. Macrophages play a pivotal role in Leishmania infection. After phagocytosis, Leishmania promastigotes enter a parasitophorous vacuole within which the macrophage can provide a safe haven for the parasite to transform into amastigotes and proliferate in a naïve host [6,31]. In an immune host, macrophages can be activated by inflam- 
Table 2: Thymidine incorporation assay of resistant $L$. (L.) amazonensis and $L$. (V.) braziliensis promastigotes to $\mathrm{NO}\left(\mathrm{NaNO}_{2}\right)$ donor in vitro.

\begin{tabular}{|c|c|c|c|c|c|c|c|c|}
\hline \multirow{2}{*}{$\begin{array}{c}L(L .) \\
\text { amazonensis }\end{array}$} & \multicolumn{8}{|c|}{$\mathrm{NaNO}_{2}$ Concentration (mM) } \\
\hline & 0 & 0.25 & 0.5 & I & 2 & 4 & 8 & 16 \\
\hline 10184 & 1804 & 2205 & 3077 & 2373 & 1284 & 1426 & 1648 & 1435 \\
\hline 436 & 1683 & 1928 & 2189 & 2544 & 2704 & 3755 & 4366 & 4047 \\
\hline 10432 & 3874 & 4240 & 4285 & 3914 & 3453 & 3312 & 2880 & 2450 \\
\hline 10048 & 826 & 1008 & 1167 & 1150 & 1243 & 1159 & 1114 & 1549 \\
\hline 10076 & 1644 & 2094 & 2870 & 2090 & 1652 & 1860 & 3874 & 3817 \\
\hline 484077 & 788 & 988 & 928 & 961 & 1009 & 1158 & 873 & 1674 \\
\hline 10047 & 5765 & 7551 & 5789 & 4416 & 9139 & 7024 & 19181 & 17839 \\
\hline $\mathrm{AC}$ & 5995 & 10034 & 9731 & 7218 & 6162 & 16305 & 10955 & 11195 \\
\hline \multirow{2}{*}{$\begin{array}{c}\text { L. (V.) } \\
\text { braziliensis }\end{array}$} & \multicolumn{8}{|c|}{$\mathrm{NaNO}_{2}$ Concentration (mM) } \\
\hline & 0 & 0.25 & 0.5 & 1 & 2 & 4 & 8 & 16 \\
\hline $133 \mid 4$ & 1626 & 2407 & 1829 & 1923 & 2340 & 3902 & 2950 & 2677 \\
\hline H.R & 1958 & 1865 & 2367 & 2549 & 1993 & 2442 & 2909 & 3511 \\
\hline
\end{tabular}

Table 3: Thymidine incorporation assay of susceptible $L$ (L.) amazonensis

\begin{tabular}{|c|c|c|c|c|c|c|c|c|}
\hline \multirow{2}{*}{$\begin{array}{c}L(L .) \\
\text { amazonensis }\end{array}$} & \multicolumn{8}{|c|}{$\mathrm{NaNO}_{2}$ Concentration (mM) } \\
\hline & 0 & 0.25 & 0.5 & I & 2 & 4 & 8 & 16 \\
\hline 8653 & 1227 & 1244 & 513 & 262 & 174 & 102 & 81 & 61 \\
\hline 9667 & 1364 & 1595 & 1255 & 1078 & 200 & 65 & 75 & 54 \\
\hline \multirow{2}{*}{$\begin{array}{c}\text { L. (V.) } \\
\text { braziliensis }\end{array}$} & \multicolumn{8}{|c|}{$\mathrm{NaNO}_{2}$ Concentration $(\mathrm{mM})$} \\
\hline & 0 & 0.25 & 0.5 & 1 & 2 & 4 & 8 & 16 \\
\hline 13323 & 2339 & 3217 & 1636 & 215 & 92 & 88 & 76 & 83 \\
\hline Lb-00I & 2213 & 2368 & 1978 & 1319 & 830 & 482 & 268 & 242 \\
\hline 13352 & 1879 & 1227 & 1318 & 870 & 868 & 474 & 326 & 196 \\
\hline 13468 & 1626 & 1796 & 169 & 78 & 73 & 85 & 89 & 97 \\
\hline
\end{tabular}

$4 \times 10^{5} \mathrm{~L}$. (L.) amazonensis and L. (V.) braziliensis promastigotes in $\mathrm{HBSS} \mathrm{pH} 5.0$ were exposed to increased $\mathrm{NaNO}_{2}$ concentrations $(0.25-16 \mathrm{mM})$ for 4 hours. The Leishmania were then washed, distributed in parasite growth medium in the presence of I $\mu$ ci/ml of ${ }^{3} \mathrm{H}-\mathrm{TdR}$. After 20 hours of incubation, the incorporation of Thymidine was measured in Beta scintillation counter (CPM). Data are mean \pm SD of NO'-resistant (Table 2) or NO'-susceptible (Table 3 ) isolates of $L$. (L.) amazonensis and $L$. (V.) braziliensis 
Table 4: MTT colorimetric assay of resistant $L$. (L.) amazonensis and $L$. (V.) braziliensis promastigotes to $\mathrm{NO}\left(\mathrm{NaNO}_{2}\right)$ donor in vitro.

\begin{tabular}{|c|c|c|c|c|c|c|c|c|}
\hline \multirow{2}{*}{$\begin{array}{c}L(L .) \\
\text { amazonensis }\end{array}$} & \multicolumn{8}{|c|}{$\mathrm{NaNO}_{2}$ Concentration $(\mathrm{mM})$} \\
\hline & 0 & 0.25 & 0.5 & 1 & 2 & 4 & 8 & 16 \\
\hline 10184 & 0.558 & 0.678 & 0.729 & 0.693 & 0.726 & 0.989 & 0.824 & 0.518 \\
\hline 436 & 0.172 & 0.231 & 0.197 & 0.257 & 0.207 & 0.197 & 0.216 & 0.265 \\
\hline 10432 & 0.098 & 0.081 & 0.072 & 0.158 & 0.131 & 0.153 & 0.154 & 0.112 \\
\hline \multirow{2}{*}{$\begin{array}{c}\text { L. (V.) } \\
\text { braziliensis }\end{array}$} & \multicolumn{8}{|c|}{$\mathrm{NaNO}_{2}$ Concentration (mM) } \\
\hline & 0 & 0.25 & 0.5 & I & 2 & 4 & 8 & 16 \\
\hline $133 \mid 4$ & 0.379 & 0.455 & 0.404 & 0.421 & 0.438 & 0.462 & 0.506 & 0.47 \\
\hline $142 \mid 4$ & 0.242 & 0.248 & 0.285 & 0.261 & 0.268 & 0.294 & 0.295 & 0.279 \\
\hline
\end{tabular}

Table 5: MTT colorimetric assay of susceptible $L$ (L.) amazonensis

\begin{tabular}{|c|c|c|c|c|c|c|c|c|}
\hline \multirow{2}{*}{$\begin{array}{c}L(L .) \\
\text { amazonensis }\end{array}$} & \multicolumn{8}{|c|}{$\mathrm{NaNO}_{2}$ Concentration $(\mathrm{mM})$} \\
\hline & 0 & 0.25 & 0.5 & 1 & 2 & 4 & 8 & 16 \\
\hline 9667 & 0.488 & 0.682 & 0.463 & 0.373 & 0.335 & 0.25 & 0.027 & 0.003 \\
\hline 9986 & 0.194 & 0.278 & 0.263 & 0.171 & 0.197 & 0.049 & 0.01 & 0.002 \\
\hline \multirow{2}{*}{$\begin{array}{c}\text { L. (V.) } \\
\text { braziliensis }\end{array}$} & \multicolumn{8}{|c|}{$\mathrm{NaNO}_{2}$ Concentration $(\mathrm{mM})$} \\
\hline & 0 & 0.25 & 0.5 & 1 & 2 & 4 & 8 & 16 \\
\hline 11155 & 0.389 & 0.478 & 0.488 & 0.432 & 0.113 & 0.025 & 0.007 & 0.004 \\
\hline 13396 & 0.292 & 0.269 & 0.28 & 0.325 & 0.224 & 0.038 & 0.012 & 0.009 \\
\hline 13323 & 0.407 & 0.265 & 0.382 & 0.684 & 0.228 & 0.157 & 0.033 & 0.014 \\
\hline Lb $00 \mathrm{I}$ & 0.249 & 0.178 & 0.191 & 0.167 & 0.169 & 0.125 & 0.091 & 0.03 \\
\hline 9291 & 0.628 & 0.645 & 0.437 & 0.253 & 0.101 & 0.033 & 0.051 & 0.02 \\
\hline 13690 & 0.558 & 0.646 & 0.448 & 0.326 & 0.13 & 0.055 & 0.023 & 0.073 \\
\hline 14183 & 0.178 & 0.166 & 0.168 & 0.096 & 0.048 & 0.035 & 0.017 & 0.009 \\
\hline 9139 & 0.446 & 0.277 & 0.221 & 0.305 & 0.182 & 0.093 & 0.047 & 0.012 \\
\hline 13183 & 0.598 & 0.39 & 0.38 & 0.373 & 0.02 & 0.036 & 0.014 & 0.007 \\
\hline 13548 & 0.547 & 0.58 & 0.894 & 0.584 & 0.382 & 0.246 & 0.053 & 0.032 \\
\hline 14349 & 0.812 & 0.556 & 0.426 & 0.404 & 0.208 & 0.108 & 0.085 & 0.086 \\
\hline 14808 & 0.261 & 0.231 & 0.251 & 0.160 & 0.096 & 0.074 & 0.024 & 0.08 \\
\hline
\end{tabular}

$1 \times 10^{6} \mathrm{~L}$. (L.) amazonensis and L. (V.) braziliensis promastigotes contained were exposed for 4 hours to increasing concentrations of the NO donor $\mathrm{NaNO}_{2}(0.25-16 \mathrm{mM})$ in HBSS pH 5.0. The cells were then washed and distributed in parasite growth medium for 20 hours. After this time the supernatants were removed and the parasites were incubated in HBSS, pH 7.0 plus $10 \mu$ l of MTT for 4 hours. Viability was a measured by the conversion of MTT to formazan and is expressed as the OD at $540 \mathrm{~nm}$. Data are mean \pm SD of NO*- resistant Leishmania isolates (Table 4) or NO* susceptible Leishmania isolates (Table 5). 
L. (L.) amazonensis

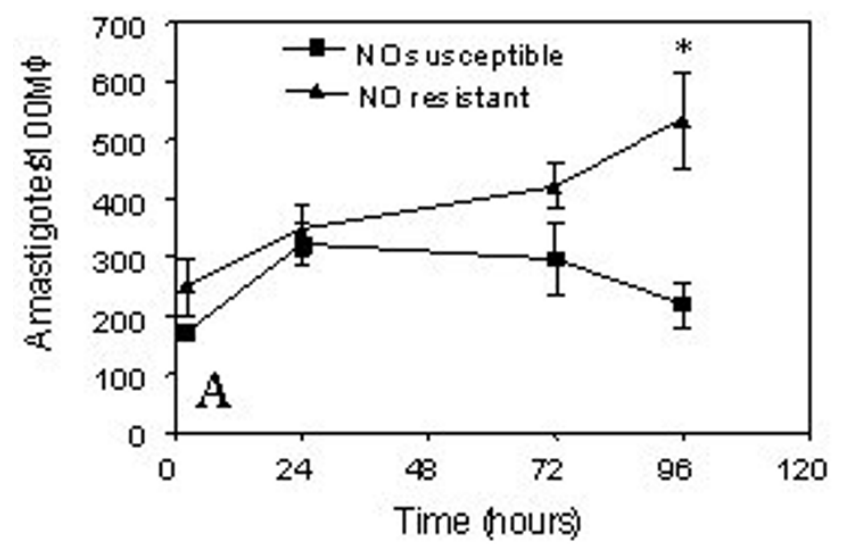

L. (L.) amazonensis

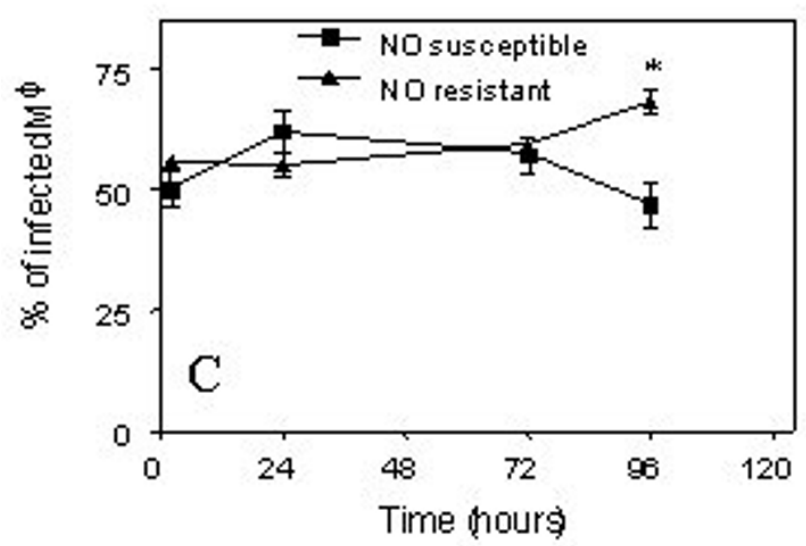

L. (V.) braziliensis

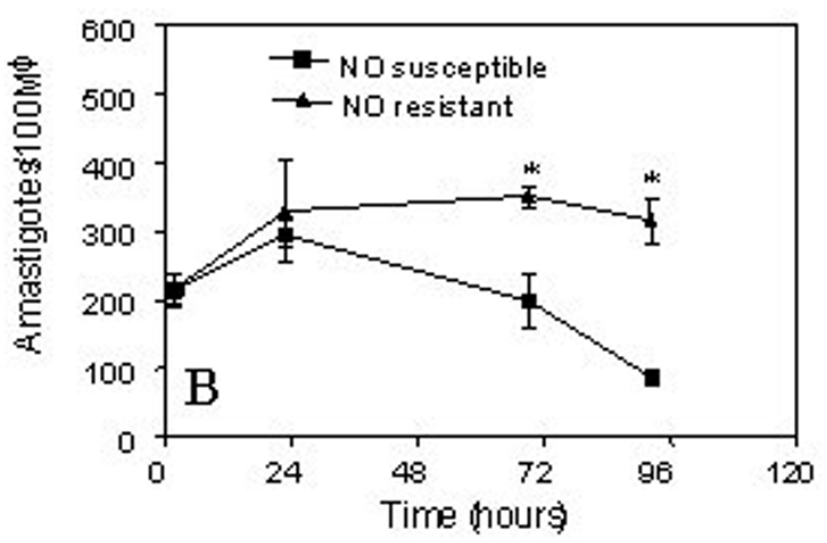

L. (V.) braziliensis

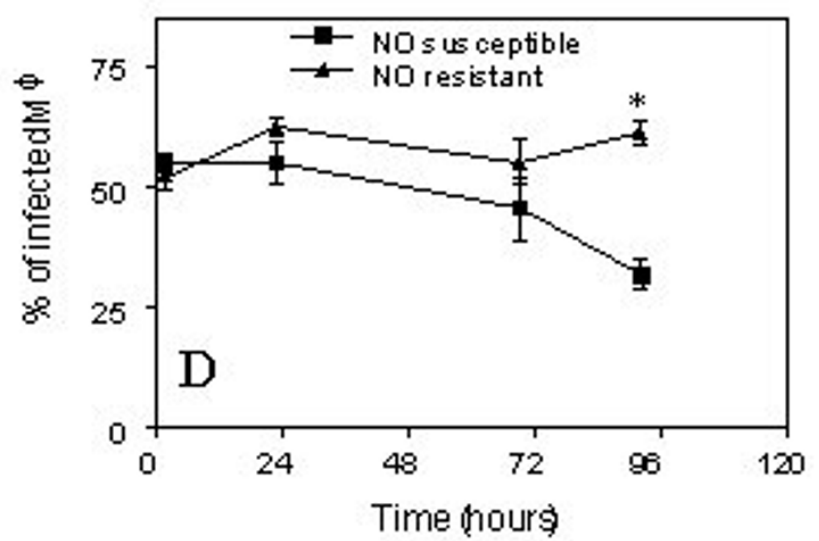

\section{Figure 2}

Infection of human macrophages with resistant or susceptible L. (V.) braziliensis or L. (L.) amazonensis isolates. Human M $\phi$ from 3 healthy donors were infected with $\mathrm{NO}^{*}$-susceptible or $\mathrm{NO}^{-}$-resistant $L$. (L.)amazonensis or $L$. (V.) braziliensis and evaluated at the designated time points for the level of intracellular infection. After monolayers were stained with Giemsa, the level of infection was expressed as number of amastigotes per $100 \mathrm{M \phi}(\mathbf{A}, \mathbf{B})$, and as the percentage of infected $M \phi(\mathbf{C}, \mathbf{D})$ for $L$. (L.) amazonensis $(\mathbf{A}, \mathbf{C})$ or $L$. (V.) braziliensis isolates (B, D). The data are expressed as the mean \pm SEM from 3 separate experiments for $L$. (V.) braziliensis and the mean \pm SEM from 4 experiments for $L$. (L.) amazonensis. Parasites were used in stationary phase of growth. Statistical analysis was performed using the paired t-test. 


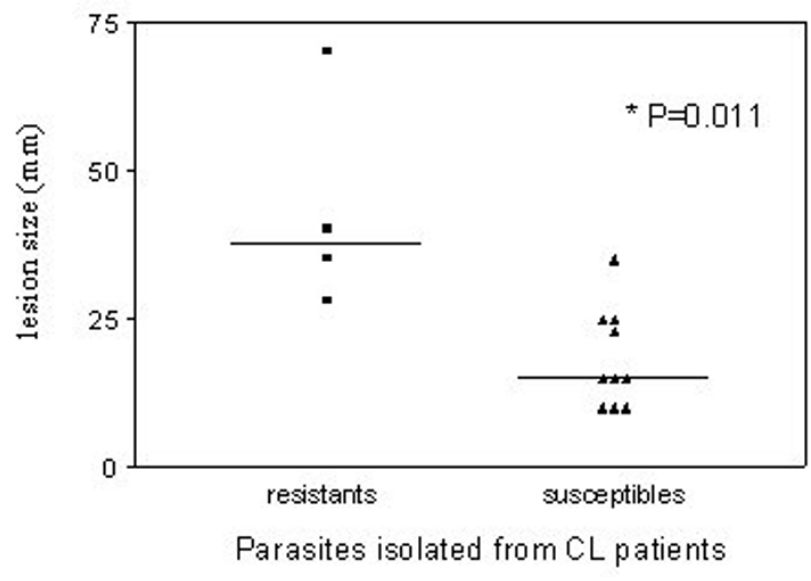

Figure 3

Association between $\mathrm{NO}^{-}$-susceptibility of the Leishmania isolate and size of the initial cutaneous lesion in $C L$ patients. Patients $(n=14)$ with cutaneous leishmaniasis were assessed for lesion size at the time of clinical presentation. This is graphed with the correlating $4 \mathrm{NO}^{-}$-resistant Leishmania (3 $L$ (L.) amazonensis and I L. (V.) braziliensis or 10 NO-susceptible Leishmania ( $2 L$ (L.) amazonensis and $8 L$ (V.) brazilienis), ( $p=0.0 \mathrm{I}$, Mann-Whitey nonparametric test).

matory cytokines to produce toxic metabolites that result in intracellular killing of Leishmania [32], or their microbicidal capacity can be dampened or abrogated by suppressive cytokines, leading to disease symptoms [33]. Specifically, TNF- $\alpha$ and IFN- $\gamma$ elaborated by macrophages or T cells synergize to up-regulate iNOS and the NADH oxidase, with the resultant production of reactive nitrogen intermediates (RNI) and reactive oxygen intermediates (ROI), respectively, that mediate killing of intracellular Leishmania [32-36]. Macrophages can alternatively produce IL-10 and TGF- $\beta$ that inhibit leishmanicidal activity. Both of these cytokines enable the parasite to grow locally and disseminate to distant sites [37-39].

Many prior studies focus on the host immune response during leishmaniasis and the ability of host cells/ cytokines to influence the outcome of Leishmania infection. During the current study we focused instead on the innate susceptibility of the parasite to leishmanicidal molecules, and their ability to resist to a host microbicidal response. We found that human $L$. (V.) braziliensis and $L$. (L.) amazonensis isolates differ in their innate susceptibility to killing by RNI in vitro, falling into two groups based on their resistance to nitric oxide. Susceptible isolates of both Leishmania species were nearly totally killed by $8 \mathrm{mM}$ of acidified $\mathrm{NaNO}_{2}$, whereas $\mathrm{NO}^{\bullet}$-resistant isolates remained viable even in $16 \mathrm{mM} \mathrm{NaNO}_{2}$. These divisions were biologically relevant, in that patients with $\mathrm{NO}^{\bullet}$ resistant cutaneous isolates produced significantly larger cutaneous ulcers than $\mathrm{NO}^{\bullet}$-susceptible Leishmania spp. isolates. Other clinical parameters were not different between $\mathrm{NO}^{\bullet}$-resistant and $\mathrm{NO}^{\bullet}$-susceptible Leishmania, arguing against a spurious association. These clinical data suggest that $\mathrm{NO}^{\bullet}$-resistance may lead to more aggressive forms of clinical disease. Differences in the time of storage in liquid nitrogen or in the length of in vitro promastigote cultivation could not explain our observations, since both $\mathrm{NO}^{\bullet}$-resistant and $\mathrm{NO}^{\bullet}$-susceptible parasites had similar time of storage and were expanded in growth medium only after selection to the present study.

Interestingly, a higher proportion of L. (L.) amazonensis isolates than $L$. (V.) braziliensis isolates were $\mathrm{NO}^{\bullet}$-resistant (73\% versus 18\%, respectively). A comparable published study showed that promastigotes and amastigotes of $L$. (L.) enriettii were more sensitive to $\mathrm{NO}^{\bullet}$ than $L$. (L.) major [21]. In conjunction with our data, this suggests that there are inter- and intra-species variations in susceptibility to toxic nitrogen products.

Isolate-specific differences in $\mathrm{NO}^{\bullet}$ susceptibility are consistent with the observed high degree of DNA polymorphism between isolates of $L$. (V.) braziliensis from several endemic areas of Brazil, documented in literature reports. Techniques used to discern these polymorphic sequences include multilocus enzyme electrophoresis (MLEE) and internal transcribed spacers (ITS) between the small and large subunits of the rRNA gene and polymorphic DNA amplification (RAPD) [40-42]. Utilizing polymorphic DNA amplification (RAPD) we reported DNA polymorphisms in $L$. (V.) braziliensis isolates from Corte de Pedra (CP), Bahia, the same location from which the current patient isolates were derived. In addition to finding polymorphism among the $L$. (V.) braziliensis isolates, we published that certain genotypes are associated with specific forms of leishmaniasis [42]. The current study extends these observations to suggest that there are biological differences between $L$. (V.) braziliensis and L. (L.) amazonensis isolates that correlate with the clinical course of disease. Murine resistance to Leishmania infections depends at least in part on $\mathrm{NO}^{\bullet}$-mediated intracellular killing of parasites through the action of iNOS [type $2 \mathrm{NO}^{\bullet}$-synthase (NOS2)]. However, the contribution of iNOS to parasite killing in human macrophages remains debated. Some reports claim a role for nitric oxide in killing of intracellular M. tuberculosis by human alveolar macrophages $[18,43]$. Our group and another has published evidence for a role of nitric oxide in macrophage microbicidal activity toward L. (L.) chagasi/infantum $[19,44]$. Nonetheless prior studies have reported difficulty in demonstrating $\mathrm{NO} \bullet$ production by human macrophages [17]. 
In addition to $\mathrm{NO}^{\bullet}$ derived from the macrophage, the Leishmania spp. themselves are able to produce NO ${ }^{\bullet}[45$ 47]. It is likely that the parasite additionally has innate mechanisms for $\mathrm{NO}^{\bullet}$ resistance in order to avoid toxicity from endogenous $\mathrm{NO}^{\bullet}$. As such, the toxic effects of exogenous $\mathrm{NO}^{\bullet}$ generated by macrophages or added experimentally would be expected to represent the sum of $\mathrm{NO}^{\bullet}$ generated by the parasite plus exogenous $\mathrm{NO}^{\circ}$, minus the amount of $\mathrm{NO}^{\bullet}$ scavenged or inactivated by innate parasite defense mechanisms. We hypothesize that such anti$\mathrm{NO} \bullet$ defenses may be utilized by the parasite for anti-oxidant defense in human infections. This hypothesis is supported by our observation that the degree of $\mathrm{NO}^{\bullet}$ resistance correlates with the severity of lesion.

We have previously reported that $L$. chagasi isolates from Brazilians with visceral leishmaniasis are susceptible to killing by $\mathrm{NO}^{\bullet}[19]$. We showed in the current study that Leishmania isolates obtained from of humans with CL differ in their susceptibility to $\mathrm{NO}^{\bullet}$. NO•-resistant Leishmania isolates were found to enter macrophages at a similar rate as susceptible strains, but they resisted intracellular killing by 72 to $96 \mathrm{~h}$ after infection. The timing of intracellular killing is consistent with the kinetics of iNOS induction, which acts 48-72 hours after infection [19]. We hypothesize that $\mathrm{NO} \bullet$ resistance is one of the mechanisms enhancing parasite survival. Alternatively or additionally, $\mathrm{NO} \bullet$ resistant parasite isolates could inhibit $\mathrm{NO}^{\bullet}$ production by macrophages, or other killing mechanisms such as ROI. Importantly, it has been shown that $M$. bovis inhibits $\mathrm{NO}^{\bullet}$ mediated killing by murine macrophages [48], as do Cryptococcus neoformans [49], Trypanosoma cruzi [50], as well, as L. (L.) amazonensis infection [51]. Other studies have reported that amastigote surface enzymes can inhibit NO• production and thereby reduce leishmanicidal activity $[52,53]$. Furthermore, the LPG-associated kinetoplastid membrane protein 11 has been reported to suppress iNOS activity, because it contains monomethylarginine residues, a structural analog of L-arginine, a known inhibitor of iNOS $[31,54]$.

The meaning of differences in $\mathrm{NO}^{\bullet}$ susceptibility amongst different Leishmania spp. isolates is not entirely straightforward. The finding that $\mathrm{NO}^{\bullet}$-resistant Leishmania exhibit improved survival within human macrophages may indicate evasion of iNOS catalyzed toxicity as in murine macrophages and a role for iNOS in control of cutaneous leishmaniasis. Alternatively, since $\mathrm{NO}^{\bullet}$ can also play a role in signaling within the infected cell, it is possible that $\mathrm{NO}^{\bullet}$ resistant isolates are changing the intracellular signaling, or resistant to alternate microbicidal effector molecules not tested here. It seems likely that $\mathrm{NO} \bullet$ resistance may contribute to the apparent increased virulence of these parasites in a human host, based on the differences in severity of the clinical parameters evaluated in the present study (significantly larger lesion size, and trend toward more resistant isolates from ML compared to CL patients). Most certainly, factors other than $\mathrm{NO}^{\bullet}$ resistance determine in part the differences in lesion size. Such factors could include the magnitude of parasite inoculum, the host immune response, and the effect of saliva. Nonetheless, it is quite interesting that the $\mathrm{NO}^{\bullet}$ resistance correlates with disease severity in our small study. Future studies are needed to better determine the clinical effects of $\mathrm{NO}^{\bullet}$ resistance on human infection and response to therapy.

\section{Conclusion}

These data suggest that nitric oxide-resistance of Leishmania isolates confers a survival benefit for the parasites inside the macrophage, and possibly exacerbates the clinical course of human leishmaniasis.

\section{Competing interests}

The author(s) declare that they have no competing interests.

\section{Authors' contributions}

AG, EMC and RPA participated equally in the study design, and AG and RPA performed all the parasites experiments.

AG, ARJ, MEW, JLH, LWR and RPA drafted the manuscript

PTGL, JMBP and IC participated in the experiments of human macrophage infection

\section{Acknowledgements}

We are grateful to Elbe Myrtes Silva and Lúcia Reis for secretarial assistance.

This work was supported by Instituto de Investigação em Imunologia (iii), NIH Tropical Medicine Research Center (P50 Al-30639), CNPq and NIH grants Al30639 (EMC, RPA), Al45540, Al48822, Al32I35 and TW0I369 (MEW), and a Merit Review grant from the Department of Veterans' Affairs (MEW). RPA, ARJ and EMC are funded by CNPq.

\section{References}

I. Bittencourt AL, Barral A: Evaluation of the histopathological classifications of American cutaneous and mucocutaneous leishmaniasis. Mem Inst Oswaldo Cruz 199|, 86:51-56.

2. Louzir H, Melby PC, Ben Salah A, Marrakchi H, Aoun K, Ben Ismail R, Dellagi K: Immunologic determinants of disease evolution in localized cutaneous leishmaniasis due to Leishmania major. $J$ Infect Dis 1998, 177:1687-1695.

3. Castes M, Trujillo D, Rojas ME, Fernandez CT, Araya L, Cabrera M, Blackwell J, Convit J: Serum levels of tumor necrosis factor in patients with American cutaneous leishmaniasis. Biol Res 1993, 26:233-238.

4. Marsden PD: Mucosal leishmaniasis due to Leishmania (Viannia) braziliensis $L(V) b$ in Tres Bracos, Bahia-Brazil. Rev Soc Bras Med Trop 1994, 27:93-101.

5. Costa JM, Marsden PD, Llanos-Cuentas EA, Netto EM, Carvalho EM, Barral A, Rosa AC, Cuba CC, Magalhaes AV, Barreto AC: Disseminated cutaneous leishmaniasis in a field clinic in Bahia, Brazil: a report of eight cases. J Trop Med Hyg 1986, 89:3 19-323. 
6. Alexander J, Russell DG: The interaction of Leishmania species with macrophages. Adv Parasitol 1992, 3 I:175-254.

7. Alexander J, Satoskar AR, Russell DG: Leishmania species: models of intracellular parasitism. J Cell Sci 1999, II $2 \mathrm{Pt}$ I 8:2993-3002

8. Liew FY, O'Donnell CA: Immunology of leishmaniasis. Adv Parasitol 1993, 32:161-259.

9. Scott P: Development and regulation of cell-mediated immunity in experimental leishmaniasis. Immunol Res 2003, 27:489-498.

10. Wilson ME, Jeronimo SM, Pearson RD: Immunopathogenesis of infection with the visceralizing Leishmania species. Microb Pathog 2005, 38: 147-160.

11. Liew FY, Parkinson C, Millott S, Severn A, Carrier M: Tumour necrosis factor (TNF alpha) in leishmaniasis. I. TNF alpha mediates host protection against cutaneous leishmaniasis. Immunology 1990, 69:570-573.

12. Liew FY, Wei XQ, Proudfoot L: Cytokines and nitric oxide as effector molecules against parasitic infections. Philos Trans $R$ Soc Lond B Biol Sci 1997, 352: I3 I I-I3 I5.

13. Bogdan $C$, Rollinghoff $M$, Diefenbach $A$ : The role of nitric oxide in innate immunity. Immunol Rev 2000, 173:17-26.

14. Green SJ, Crawford RM, Hockmeyer JT, Meltzer MS, Nacy CA Leishmania major amastigotes initiate the L-argininedependent killing mechanism in IFN-gamma-stimulated macrophages by induction of tumor necrosis factor-alpha. Immunol 1990, 145:4290-4297.

15. Evans TG, Thai L, Granger DL, Hibbs JB Jr.: Effect of in vivo inhibition of nitric oxide production in murine leishmaniasis. Immunol 1993, I5 I:907-9I5.

16. Assreuy J, Cunha FQ, Epperlein M, Noronha-Dutra A, O'Donnell CA, Liew FY, Moncada S: Production of nitric oxide and superoxide by activated macrophages and killing of Leishmania major. Eur I Immunol 1994, 24:672-676.

17. Murray HW, Teitelbaum RF: L-arginine-dependent reactive nitrogen intermediates and the antimicrobial effect of activated human mononuclear phagocytes. I Infect Dis 1992 165:513-517.

18. Nicholson S, Bonecini-Almeida Mda G, Lapa e Silva JR, Nathan C, Xie QW, Mumford R, Weidner JR, Calaycay J, Geng J, Boechat N, et al: Inducible nitric oxide synthase in pulmonary alveolar macrophages from patients with tuberculosis. J Exp Med 1996, 183:2293-2302.

19. Gantt KR, Goldman TL, McCormick ML, Miller MA, Jeronimo SM, Nascimento ET, Britigan BE, Wilson ME: Oxidative responses of human and murine macrophages during phagocytosis of Leishmania chagasi. J Immunol 200I, 167:893-90I.

20. Bogdan C: Nitric oxide and the immune response. Nat Immunol 200I, 2:907-916

21. Mauel J, Ransijn A: Leishmania spp.: mechanisms of toxicity of nitrogen oxidation products. Exp Parasitol 1997, 87:98-I I I.

22. Romao PR, Tovar J, Fonseca SG, Moraes RH, Cruz AK, Hothersall JS, Noronha-Dutra AA, Ferreira SH, Cunha FQ: Glutathione and the redox control system trypanothione/trypanothione reductase are involved in the protection of Leishmania spp. against nitrosothiol-induced cytotoxicity. Braz J Med Biol Res 2006 , 39:355-363.

23. Paramchuk WJ, Ismail SO, Bhatia A, Gedamu L: Cloning, characterization and overexpression of two iron superoxide dismutase cDNAs from Leishmania chagasi: role in pathogenesis. Mol Biochem Parasitol 1997, 90:203-221.

24. Meshnick SR, Eaton JW: Leishmanial superoxide dismutase: a possible target for chemotherapy. Biochem Biophys Res Commun 198I, 102:970-976.

25. Vickers TJ, Wyllie S, Fairlamb AH: Leishmania major elongation factor IB complex has trypanothione S-transferase and peroxidase activity. J Biol Chem 2004, 279:49003-49009.

26. Levick MP, Tetaud E, Fairlamb AH, Blackwell JM: Identification and characterisation of a functional peroxidoxin from Leishmania major. Mol Biochem Parasitol 1998, 96:125-137.

27. Miller MA, McGowan SE, Gantt KR, Champion M, Novick SL, Andersen KA, Bacchi CJ, Yarlett N, Britigan BE, Wilson ME: Inducible resistance to oxidant stress in the protozoan Leishmania chagasi. J Biol Chem 2000, 275:33883-33889.
28. Fang FC: Perspectives series: host/pathogen interactions. Mechanisms of nitric oxide-related antimicrobial activity. J Clin Invest 1997, 99:2818-2825.

29. Cupolillo E, Grimaldi G Jr., Momen H: A general classification of New World Leishmania using numerical zymotaxonomy. Am J Trop Med Hyg 1994, 50:296-3II.

30. Wilson ME, Andersen KA, Britigan BE: Response of Leishmania chagasi promastigotes to oxidant stress. Infect Immun 1994, 62:5|33-5|4|.

3I. Bogdan C, Gessner A, Solbach W, Rollinghoff M: Invasion, control and persistence of Leishmania parasites. Curr Opin Immunol 1996, 8:517-525.

32. Murray HW, Nathan CF: Macrophage microbicidal mechanisms in vivo: reactive nitrogen versus oxygen intermediates in the killing of intracellular visceral Leishmania donovani. J Exp Med 1999, 189:74I-746.

33. Reiner NE: Altered cell signaling and mononuclear phagocyte deactivation during intracellular infection. Immunol Today 1994, I5:374-38|

34. Scott P: IFN-gamma modulates the early development of Th I and Th2 responses in a murine model of cutaneous leishmaniasis. J Immunol I99I, I 47:3149-3I55.

35. Vouldoukis I, Riveros-Moreno V, Dugas B, Ouaaz F, Becherel P, Debre P, Moncada S, Mossalayi MD: The killing of Leishmania major by human macrophages is mediated by nitric oxide induced after ligation of the Fc epsilon RII/CD23 surface antigen. Proc Natl Acad Sci U S A 1995, 92:7804-7808.

36. Kumar P, Pai K, Pandey HP, Sundar S: NADH-oxidase, NADPH. oxidase and myeloperoxidase activity of visceral leishmaniasis patients. J Med Microbiol 2002, $51: 832-836$.

37. Bogdan C, Vodovotz Y, Nathan C: Macrophage deactivation by interleukin 10. J Exp Med 199I, 174:1549-1555.

38. Barral-Netto M, Badaro R, Barral A, Almeida RP, Santos SB, Badaro F, Pedral-Sampaio D, Carvalho EM, Falcoff E, Falcoff R: Tumor necrosis factor (cachectin) in human visceral leishmaniasis. $J$ Infect Dis 1991, 163:853-857.

39. Wilson ME, Young BM, Davidson BL, Mente KA, McGowan SE: The importance of TGF-beta in murine visceral leishmaniasis. J Immunol 1998, 161:6148-6155.

40. Cupolillo E, Momen H, Grimaldi G Jr.: Genetic diversity in natural populations of New World Leishmania. Mem Inst Oswaldo Cruz 1998, 93:663-668.

4I. Cupolilo SM, Souza CS, Abreu-Silva AL, Calabrese KS, Goncalves da Costa SC: Biological behavior of Leishmania (L.) amazonensis isolated from a human diffuse cutaneous leishmaniasis in inbred strains of mice. Histol Histopathol 2003, 18:1059-1065.

42. Schriefer A, Schriefer AL, Goes-Neto A, Guimaraes LH, Carvalho LP, Almeida RP, Machado PR, Lessa HA, de Jesus AR, Riley LW, Carvalho EM: Multiclonal Leishmania braziliensis population structure and its clinical implication in a region of endemicity for American tegumentary leishmaniasis. Infect Immun 2004, 72:508-5।4.

43. Rockett KA, Brookes R, Udalova I, Vidal V, Hill AV, Kwiatkowski D I,25-Dihydroxyvitamin $D 3$ induces nitric oxide synthase and suppresses growth of Mycobacterium tuberculosis in a human macrophage-like cell line. Infect Immun 1998, 66:53|4-532I.

44. Vouldoukis I, Becherel PA, Riveros-Moreno V, Arock M, da Silva O, Debre $P$, Mazier D, Mossalayi MD: Interleukin- 10 and interleukin-4 inhibit intracellular killing of Leishmania infantum and Leishmania major by human macrophages by decreasing nitric oxide generation. Eur J Immunol 1997, 27:860-865.

45. Basu NK, Kole L, Ghosh A, Das PK: Isolation of a nitric oxide synthase from the protozoan parasite, Leishmania donovani. FEMS Microbiol Lett 1997, 1 56:43-47.

46. Genestra M, Souza WJ, Guedes-Silva D, Machado GM, Cysne-Finkelstein L, Bezerra RJ, Monteiro F, Leon LL: Nitric oxide biosynthesis by Leishmania amazonensis promastigotes containing a high percentage of metacyclic forms. Arch Microbiol 2006, 185:348-354.

47. Genestra M, Guedes-Silva D, Souza WJ, Cysne-Finkelstein L, SoaresBezerra RJ, Monteiro FP, Leon LL: Nitric oxide synthase (NOS) characterization in Leishmania amazonensis axenic amastigotes. Arch Med Res 2006, 37:328-333.

48. Hanano R, Kaufmann SH: Nitric oxide production and mycobacterial growth inhibition by murine alveolar macrophages: 
the sequence of rIFN-gamma stimulation and Mycobacterium bovis BCG infection determines macrophage activation. Immunol Lett 1995, 45:23-27.

49. Kawakami K, Zhang T, Qureshi MH, Saito A: Cryptococcus neoformans inhibits nitric oxide production by murine peritoneal macrophages stimulated with interferon-gamma and lipopolysaccharide. Cell Immunol 1997, I 80:47-54.

50. Pakianathan DR, Kuhn RE: Trypanosoma cruzi affects nitric oxide production by murine peritoneal macrophages. J Parasitol 1994, 80:432-437.

5I. Balestieri FM, Queiroz AR, Scavone C, Costa VM, Barral-Netto M, Abrahamsohn Ide A: Leishmania (L.) amazonensis-induced inhibition of nitric oxide synthesis in host macrophages. Microbes Infect 2002, 4:23-29.

52. Descoteaux A, Turco SI: Glycoconjugates in Leishmania infectivity. Biochim Biophys Acta 1999, I 455:341-352.

53. Nathan C, Xie QW: Nitric oxide synthases: roles, tolls, and controls. Cell 1994, 78:915-918.

54. Jardim A, Funk V, Caprioli RM, Olafson RW: Isolation and structural characterization of the Leishmania donovani kinetoplastid membrane protein-II, a major immunoreactive membrane glycoprotein. Biochem J 1995, 305 ( Pt I):307-3 I3.

\section{Pre-publication history}

The pre-publication history for this paper can be accessed here:

http://www.biomedcentral.com/1471-2334/7/7/prepub

Publish with Bio Med Central and every scientist can read your work free of charge

"BioMed Central will be the most significant development for disseminating the results of biomedical research in our lifetime. "

Sir Paul Nurse, Cancer Research UK

Your research papers will be:

- available free of charge to the entire biomedical community

- peer reviewed and published immediately upon acceptance

- cited in PubMed and archived on PubMed Central

- yours - you keep the copyright 